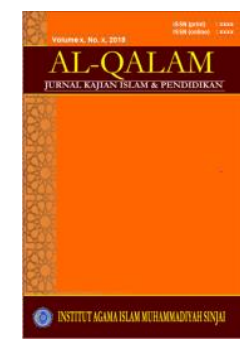

AL-QALAM

Jurnal Kajian Islam \& Pendidikan

Volume 8, No. 2, 2016

ISSN (print) : 1858-4152

ISSN (online) : xxxx-xxxx

Homepage : http://journal.iaimsinjai.ac.id/index.php/al-qalam

\title{
SEJARAH PERBANDINGAN SISTEM PENDIDIKAN DENMARK DENGAN SISTEM PENDIDIKAN INDONESIA
}

\author{
Oleh: Hardianto Rahman ${ }^{1}$
}

$* * * *$

\begin{abstract}
Abstrak
Tulisan ini bertujuan untuk mengetahui sistem pendidikan di Negara Denmark, untuk membandingkan sistem pendidikan di Denmark dengan sistem pendidikan di Indonesiadan mencari dan mendiskusikan system pendidikan Denmark yang dapat di adopsi dalam system pendidikan Indonesia. Metode yang digunakan dalam penelitian ini diantaranya yaitu: metode kritis, , metode dialektis dan metode skolastik. Penelitian ini termasuk dalam penelitian kepustakaan. Penulis berusaha mencari data-data, teori-teori yang berkaitan dengan persoalan yang diangkat dalam berbagai literature atau referensi yang ditemukan penulis kemudian dibandingkan dengan menggunakan metode tersebut di atas. Kesimpulan dari penelitian ini adalah: (1) Pendidikan di Denmak dijiwai oleh prinsip prinsip dasar yang berlaku dalam kehidupan sosial budaya masyarakat Denmak seperti kebebasan berpendapat, self-control, persamaan serta saling mempercayai dan menghargai satu sama lain; (2) Pendidikan di Denmark mengandung banyak sisi positif yang berguna bagi perkembangan mahasiswa baik dari sisi akademis mauapun non-akademis. Sisi positif ini dirasa masih jauh lebih banyak daripada sisi negatifnya
\end{abstract}

Kata Kunci: Sistem, Pendidikan, Negara Dan Denmark

\section{PENDAHULUAN}

\section{A. Latar Belakan}

$\mathrm{J}$

ika ingin tahu bagaimana masa depan suatu bangsa, maka lihatlah pendidikannya. Sebab, pendidikan adalah salah satu komponen terpenting yang menentukan nasib suatu bangsa. Fakta membuktikan bahwa negara-negara maju pasti memiliki sistem pendidikan yang baik. Begitu pun dengan negara-negara yang dulunya berada dalam kondisi yang tidak baik, mulai terangkat derajatnya dengan sedikit demi sedikit membenahi sistem pendidikan mereka.

Salah satu Negara yang mempunyai perhatian yang sangat tinggi terhadap mutu penididikan ialah Negara Denmark. Denmark salah satu Negara Skandinavia yang menganut sistem ekonomi kapitalis pasar campuran sekaligus kesejahteraan sosial. Negara ini mempunyai pendapatan tertinggi di dunia. Berdasarkan laporan majalah Forbes, Denmark memiliki iklim bisnis terbaik. Dari tahun 2006 sampai 2008, survey mengatakan Denmark adalah "tempat yang paling menyenangkan di dunia", dipandang dari standar kesehatan, kesejahteraan, dan pendidikan. Sementara, survey Global Peace Index tahun 2009

\footnotetext{
${ }^{1}$ Dosen Tetap Institut Agama Islam (IAI) Muhammadiyah Sinjai
} 


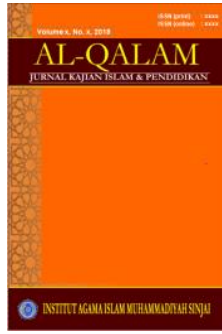

AL-QALAM

Jurnal Kajian Islam \& Pendidikan

Volume 8, No. 2, 2016

ISSN (print) : 1858-4152

ISSN (online) : xxxx-xxxx

Homepage : http://journal.iaimsinjai.ac.id/index.php/al-qalam

mengatakan Denmark menduduki posisi negara paling damai kedua di dunia, setelah Selandia Baru. Di tahun 2009, Denmark adalah salah satu dari negara yang paling tidak korup di dunia berdasarkan Indeks Persepsi Korupsi, posisi kedua setelah Selandia Baru. ${ }^{2}$

\section{A. Tujuan Penulisan}

1. Untuk mengetahui sistem pendidikan di Negara Denmark

2. Untuk membandingkan system pendidikan di Denmark dengan sistem pendidikan di Indonesia

3. Mencari dan mendiskusikan system pendidikan Denmark yang dapat di adopsi dalam sistem pendidikan Indonesia

\section{B. Manfaat Penulisan}

1. Menjadi bahan pembanding dalam kebijakan-kebijakan sistem pendidikan di berbagai Negara khususnya di Indonesia

2. Menjadi referensi bagi para pendidikan dalam melakukan praktek pendidikan baik formal maupun informal

\section{PEMBAHASAN}

\section{A. Negara Denmark}

\section{Profil Negara Denmark}

Denmark atau Kerajaan Denmark (bahasa Denmark: Kongeriget Danmark) adalah negara Nordik yang paling kecil dan paling selatan. Denmark teletak di Eropa Utara sehingga termasuk Uni Eropa (sejak tahun 1973). Ibu kota (dan kota terbesar) di Denmark adalah Copenhagen.

Denmark berbatasan dengan Laut Baltik dan Laut Utara. Satu-satunya negara yang berbatasan darat dengan Denmark adalah Jerman sedangkan yang berbatasan laut adalah Swedia di timur laut dan Norwegia di utara. Wilayahnya meliputi sebuah semenanjung di Jerman utara bernama Jylland (Jutlandia), Kepulauan $\quad$ Fyn (Funen), Sjælland (Zealand), $\quad$ VendsysselThy, Lolland, Falster, Bornholm dan ratusan pulau kecil, yang sering disebut kepulauan Denmark.

Negara ini menganut monarki konstitusional dan sistem pemerintahan parlementer. Denmark memiliki satu pemerintah pusat dan 98 munisipalitas (subdivisi administratif terkecil yang pimpinannya diangkat melalui suatu proses pemilihan demokratis) sebagai pemerintah daerah. Denmark adalah salah satu pendiri NATO dan OECD.

Denmark merupakan penganut ekonomi kapitalis pasar campuran yang memiliki pendapatan tertinggi di dunia. Berdasarkan majalah Forbes, Denmark adalah negara yang memiliki iklim bisnis terbaik. Dari tahun 2006 sampai 2008, survey mengatakan bahwa Denmark adalah "tempat yang paling menyenangkan di dunia", dipandang dari standar kesehatan, kesejahteraan, dan pendidikan. Survey Global Peace Index tahun 2009 mengatakan bahwa Denmark menduduki posisi negara paling damai kedua di dunia, setelah Selandia Baru. Di tahun 2009, Denmark adalah salah satu dari negara yang paling tidak korup di dunia berdasarkan Indeks Persepsi Korupsi, posisi kedua setelah Selandia Baru 3

\footnotetext{
${ }^{2}$ lihat di: http://lifestyle.kompasiana.com/catatan/2011/04/22/belajar-dari-denmark/

${ }^{3} \mathrm{http}$ ://en.wikipedia.org/wiki/Denmark.
} 


\section{Filosofi/ Prinsip Hidup Masyarakat}

Prinsip-prinsip dasar kehidupan di Denmark adalah kebebasan berdasarkan persamaan dan saling mempercayai di antara anggota masyarakat. Prinsip-prinsip tersebut mendasari seluruh kegiatan bernegara di Denmark, termasuk di bidang pendidikan. ${ }^{4}$

\section{Sistem Pendidikan Denmark}

Denmark adalah negara kaya dengan penduduk hanya 5,5 juta yang menggratiskan semua level pendidikannya, tidak hanya bagi warga negaranya, bahkan untuk warga Uni Eropa lain. Siapapun dipersilahkan sekolah sampai tingkat setinggi-tingginya. Itu adalah salah satu penyebab kenapa hampir semua penduduk Denmark melanjutkan ke perguruan tinggi. Namun bagi warga negara yang merasa tidak memiliki kemampuan akademis dan memilih untuk masuk ke pendidikan vokasi, disediakan jalur vokasi mulai dari tingkat sekolah menengah (secondary level) dengan sebutan business atau engineering high school. Sistem pendidikan juga dibuat semudah mungkin agar seluruh warga bisa dengan mudah mengaksesnya.

Denmark memberlakukan ujian akhir standar nasional bagi seluruh calon lulusan sekolah menengah atas. Ujian dilakukan serentak di seluruh negeri, penyelenggaraan dilakukan di sekolah masing-masing. Tidak seheboh di Indonesia, namun prinsipnya sama. Tidak ada entrance exam (seleksi masuk) ke perguruan tinggi, namun nilai hasil ujian akhir SMA yang langsung dipakai sebagai dasar untuk diterima masuk ke perguruan tinggi.

Denmark adalah negeri yang mengandalkan pada knowledge economy, mereka sadar sepenuhnya bahwa hanya warga yang punya pendidikan baiklah yang akan membuat mereka survive dan menang dalam persaingan global. Ketika ditanya apakah kemudahan seperti itu tidak membuat mereka terlena dan menjadi malas, tidak ada persaingan karena semua sudah tertata dan terjamin. Dengan yakin sang mahasiswa Denmark menjawab bahwa dia tidak melihat hal itu terjadi. Sambil bergurau dia mengatakan bahwa warga negeri dingin seperti Denmark tidak bisa bermalas-malasan karena pasti akan beku kedinginan

Di Denmark, pendidikan diwajibkan bagi anak berusia tujuh hingga enam belas tahun. Pendidikan pra sekolah dapat diberikan sebelum usia enam tahun. Ada pula jenis pendidikan alternatif yang diambil oleh sekitar $60 \%$ remaja yang umumnya belum memutuskan perencanaan karir mereka maupun yang akan melanjutkan ke jenjang pendidikan yang lebih tinggi. 99\% dari remaja tersebut dapat menyelesaikan wajib belajar dalam waktu sekitar 9 hingga 10 tahun. Pada saat ini, 95\% dari mereka melanjutkan pendidikannya pada program pendidikan pasca 16 tahun. Ada 3 kategori utama pada pelatihan dan pendidikan tersebut, ${ }^{5}$ yaitu:

a. Program pelatihan dan pendidikan kejuruan diikuti oleh sekiitar $35 \%$ alumni sekolah

b. Pendidikan kejuruan tingkat lanjut diikuti sekitar $15 \%$ alumni sekolah

c. Pendidikan lanjutan umum diikuti oleh sekitar $45 \%$ alumni sekolah.

Program VET merupakan bagian dari sistem pendidikan tingkat SMA. Tujuan dari program tersebut tidak hanya memberikan pendidikan kejuruan bagi para siswa, yang telah diketahui secara formal dan sesuai dengan permintaan pasar, namun juga memberikan

\footnotetext{
${ }^{4}$ Lihat di http://www.denmark.dk/en

${ }^{5}$ Ibid.
} 


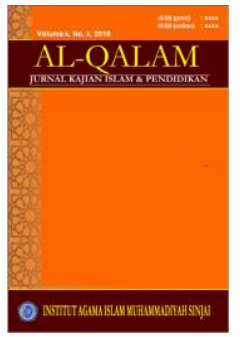

AL-QALAM

Jurnal Kajian Islam \& Pendidikan

Volume 8, No. 2, 2016

ISSN (print) : 1858-4152

ISSN (online) : xxxx-xxxx

Homepage : http://journal.iaimsinjai.ac.id/index.php/al-qalam

kualifikasi personal dan umum yang dapat memberikan kesempatan untuk hidup dan belajar sebagai warga negara yang aktif.

\section{a. Jenjang Persekolahan}

\section{Pra-pendidikan dasar:}

Vuggestue/daycare/tempat penitipan anak (usia 0.5-3 tahun) merupakan tempat penitipan anak. Kegiatan utamanya adalah merawat anak dan menanamkan rutinitas sehari-hari yang akan jadi dasar kegiatan di TK dan selanjutnya.

\section{a. Børnehave/Taman Kanak-Kanak (3-6 tahun)}

Di TK, anak-anak belum diajarkan membaca dan menulis. Kegiatan difokuskan pada kegiatan-kegiatan untuk mengembangkan kemampuan motorik, bahasa dan sosial anak, seperti bermain, bercerita dan berjalan-jalan bersama. Selama TK, kebiasaan dan rutinitas yang telah ditanamkan di tempat penitipan anak terus diperkuat.

\section{b. Pendidikan Dasar (usia 7-16 tahun)}

Terdiri dari kelas 1-9 (wajib diikuti oleh semua anak yang tinggal di Denmark) dan kelas 10 (Pilihan. Diperuntukkan bagi murid yang belum siap secara akademis dan atau secara mental untuk melanjutkan ke jenjang pendidikan lebih tinggi). Pendidikan dasar di selenggrakan di sekolah negeri (folkeskole) dan swasta. Sekitar $88 \%$ murid bersekolah di folkeskole. Sebelum masuk pendidikan dasar, terdapat kelas 0 yang merupakan peralihan dari TK ke pendidikan dasar. Materi ajar diberikan secara bertahap. Ada yang diberikan di seluruh tahun ajaran, ada yang hanya diberikan di kelas 1-7, 4-10 dan 8-106.

Metoda pendidikan dasar diarahkan agar murid memiliki kepercayaan diri dan mandiri. Hal ini dicapai lewat komunikasi terbuka antara murid, orang tua dan sekolah. Pertemuan antara orang tua dan sekolah (biasanya melibatkan murid yang bersangkutan) diadakan minimal setahun dua kali.

Tidak ada ujian dan pemberian nilai sampai kelas 8 (masalah ini sedang menjadi bahan perdebatan di Denmark), hanya pemberian tugas-tugas. Prinsip penggunaan teknologi informasi diterapkan sejak dini. Luasnya penggunaan internet di masyarakat Denmark memungkinkan guru untuk meng-upload tugas di internet sehingga orang tua juga bisa melihat tugas-tugas yang diberikan guru kepada anak mereka.

Salah satu fokus pendidikan dasar di Denmark adalah pengembangan kemampuan sosial anak dan mempersiapkan mereka menjadi anggota masyarakat yang benar-benar mengerti hak dan tanggung jawabnya. Prinsip-prinsip utama yang diterapkan adalah nilai-nilai demokrasi, kebebasan dan menjunjung tinggi persamaan.

\section{Pendidikan Menengah}

Gymnasium/SMU (3 tahun) dan sekolah-sekolah setingkat Gymnasium yang mengorientasikan diri pada bidang tertentu (3 tahun)

Fokus pendidikan di gymnasium adalah mempersiapkan anak didik untuk mengikuti pendidikan tinggi. Sejak 2005, pendidikan di Gymnasium menawarkan 3 pilihan arah studi: bahasa, sains dan creative studies. Pelajar bisa mengkombinasikan pelajaran-pelajaran dari ketiga bidang tersebut.

\footnotetext{
${ }^{6}$ http://en.wikipedia.org/wiki/Danish_Folkeskole_Education
} 


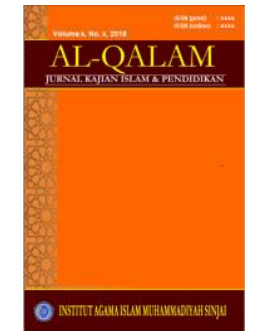

AL-QALAM

Jurnal Kajian Islam \& Pendidikan

Volume 8, No. 2, 2016

ISSN (print) : 1858-4152

ISSN (online) : xxxx-xxxx

Homepage : http://journal.iaimsinjai.ac.id/index.php/al-qalam

Sekolah setingkat Gymnasium yang mengorientasikan diri pada bidang tertentu Seperti juga Gymnsium hanya saja lebih memfokuskan diri di bidang tertentu, misalnya (lihat bagan Jenjang Pendidikan di Denmark): HHX (sejenis SMEA di Indonesia), HTX (sejenis STM di Indonesia).

Walaupun kurikulum di sekolah-sekolah ini mengandung praktek, tetapi muatan teori tetap tinggi karena tujuan utama pendidikan ini adalah mempersiapkan murid untuk melanjutkan pendidikan ke tingkat yang lebih tinggi (universitas/college) dengan jurusan yang sesuai.

\section{a. Vocational Education dan pendidikan kejuruan lain yang setingkat dengannya (3-4 tahun)}

Pendidikan kejuruan terdiri dari teori dan praktek (magang/ apprenticeship), yang minimal memakan setengah dari seluruh waktu pendidikan. Lulusannya dianggap siap untuk bekerja di bidang yang bersangkutan. Contoh pendidikan jenis ini adalah pendidikan untuk menjadi tukang kayu dan bangunan, gardener, pekerja salon, atau yang memfokuskan diri di bidang sosial dan kesehatan masyarakat.

Pendidikan kejuruan merupakan bagian sangat penting dari sistem pendidikan di Denmark. Tradisi magang berakar kuat dari abad pertengahan dan saat ini sudah terorganisasi dan terstandarnisasi dengan sangat baik. Ijazah Vocational Education bisa digunakan untuk melanjutkan pendidikan jangka pendek di akademi profesi atau pun college (dengan bidang yang sama).

Denmark mempunyai sekitar 140 lembaga pendidikan kejuruan, yang dapat dikelompokkan menjadi empat kelompok sesuai dengan bidangnya, yaitu:

1. Lembaga pendidikan teknik ( pekerjaaan yang memberikan jasa ilmu teknik, industri dan kerajinan tangan )

2. Lembaga pendidikan bisnis ( perdagangan dan administrasi)

3. Lembaga pendidikan pertanian ( pertanian)

4. Lembaga pendidikan kesehatan dan sosial

Lembaga pendidikan kejuruan di Denmark tidak hanya menawarkan palatihan dan pendidikan kejuruan, namun juga pendidikan teknik dan perdagangan setelah SMA.

b. Pendidikan Tinggi Ehrvervsakademier/Akademi Profesi (2-2.5 tahun) Professionhøjskoler/University College/ Pendidikan Tinggi Profesi (3-4.5 tahun)

Terdapat lebih dari 150 institusi pendidikan tinggi khusus di Denmark. Sekitar sepertiga dari jumlah ini menyediakan pendidikan berorientasi profesi jangka pendek dan sekitar dua pertiga menyediakan pendidikan berorientasi profesi jangka menengah (medium). Banyak dari college- college ini hanya memiliki 400-600 mahasiswa yang mendalami bidang-bidang tertentu. College- college ini biasanya bekerja sama dengan college-college lain dan universitas. 
Volume 8, No. 2, 2016

ISSN (print) : 1858-4152

ISSN (online) : xxxx-xxxx

Homepage : http://journal.iaimsinjai.ac.id/index.php/al-qalam

1. Universitas/ research-based education:

Bachelor (3 tahun) -Master (2 tahun) -Phd (3 tahun) Denmark memiliki 11 universitas. Lima universitas memiliki fakultas yang berbeda (multi-faculties) dan 6 lainnya bergerak khusus di bidang tertentu seperti engineering, pendidikan, ilmu pengetahuan alam, pertanian, farmasi atau pendidikan bisnis.

\section{Program Bachelor dan Master}

Program Bachelor dan Master biasanya terintegrasi. Total pendidikan 5 tahun (terdiri dari bachelor 3 tahun dan master 2 tahun). Program Master International berlangsung selama 2 tahun (mahasiswa international biasanya bergabung di tahun ke-4 pendidikan mahasiswa lokal). -Kuliah dan project Implementasi dari kurikulum di tiap universitas dapat bervariasi, namun secara umum mata kuliah yang diajarkan terbagi menjadi dua jenis, yaitu: mata kuliah wajib dan mata kuliah pilihan. Selain mata kuliah, komponen wajib lain adalah "proyek" ya ng harus dikerjakan secara berkelompok. Proyek ini biasanya implementasi dari sistem "Prob lem Based Learning" atau PBL (mengenai PBL akan dibahas di sub bab tersendiri).

Sistem kredit yang digunakan adalah ECTS (European Credit Transfer and Accumulation System). Evaluasi dan sistem penilaian Secara teknis, evaluasi dari mata kuliah wajib berupa ujian akhir, yang dapat berupa ujian tertulis ataupun lisan. Sedangkan evaluasi dari mata kuliah pilihan dapat berupa ujian khusus seperti mata kuliah wajib, dan dapat pula terintegrasi dengan ujian proyek. Sistem penilaian di Denmark secara umum dapat dibagi dua: lulus atau tidak lulus, dan sistem nilai yang memiliki beberapa tingkatan ${ }^{7}$

\section{Project Based Learning (PBL)}

PBL adalah sistem belajar di mana mahasiswa (atau kelompok mahasiswa) diarahkan untuk bekerja dengan suatu masalah yang terkait dengan satu mata kuliah (atau dengan tema umum satu semester). Mereka harus mendefinisikan masalah tersebut, menganalisis, mencari solusi, kemudian mengevaluasi solusi tersebut dan mendokumentasikan proyek dalam sebuah laporan. Proyek dan laporannya akan dipresentasikan dan diuji di akhir semester.

Penerapan PBL tergantung dari universitas yang bersangkutan. Ada yang menerapkan pada hanya beberapa topik atau mata kuliah dalam satu semester, ada yang menerapkannya untuk seluruh topik dalam satu semester.

Universitas di Denmark yang menerapkan PBL untuk seluruh proses pendidikan dari Bachelor sampai Master adalah Aalborg University (AAU) di North Jutland. AAU merupakan salah satu dari sedikit universitas di dunia yang menerapkan PBL secara total sebagai metoda pendidikannya. ${ }^{8}$

\section{Program PhD.}

\footnotetext{
${ }^{7}$ http://eacea.ec.europa.eu/education/eurydice/documents/eurybase/eurybase full reports/DK EN.

${ }^{8} \mathrm{http}: / /$ ppidenmark2010.wordpress.com/2010/10/02/pendidikan-di-denmark-jenjang-s1-s3
} 
Program PhD di Denmark berlangsung selama 3 tahun, namun dalam kenyataan banyak mahasiswa PhD yang membutuhkan waktu 1/2 - 1 1/2 tahun lebih lama. Selama melaksanakan program tersebut mahasiswa :

a. membuat Study Plan di awal program Phd yang merupakan rencana detil tentang apa yang akan dikerjakan selama program $\mathrm{PhD}$. Penulisan study plan harus mengacu pada format aturan yang dibuat oleh Doctoral/Phd. School di fakultas yang bersangkutan. Apabila rencana studi itu dianggap memenuhi syarat dan telah disetujui oleh Phd. School, mahasiswa yang bersangkutan resmi terdaftar sebagai $\mathrm{PhD}$ student.

b. Study plan ini wajib di-update setiap 6 bulan. Phd. School akan memberi masukan ttg kekurangan apa saja yang harus diselesaikan untuk report selanjutnya. Masukan ini akan dibicarakan bersama antara mahasiswa Phd. yang bersangkutan dan supervisornya.

c. melakukan riset mandiri di mana yang bersangkutan mengambil inisiatif mengembangkan tema riset dan pembimbing berfungsi sebagai teman berdiskusi

d. mengikuti kuliah, seminar, workshop sejumlah setara dengan 30 ECTS/ semester. Jenis dan topik kuliah, serta waktu mengikuti kuliah tersebut (misal di awal, tengah atau akhir program $\mathrm{Ph} . \mathrm{D}$ ) dibicarakan bersama dengan supervisor.

\section{B. SISTEM PENDIDIKAN DI INDONESIA}

\section{FALSAFAH PENDIDIKAN DI INDONESIA}

PASAL 2 UU NO 2 TAHUN 1989 DISEBUTKAN BAHWA "PENDIDIKAN NASIONAL BERDASARKAN PANCASILA DAN UUD 1945". DENGAN BEGITU SETIAP SATUAN PENDIDIKAN YANG DISELENGGARAKAN BERDASARKAN PANCASILA DAN UUD 1945 DAPAT DIKATEGORIKAN SEBAGAI DAN MASUK DALAM KESATUAN SISTEM PENDIDIKAN NASIONAL.

\section{TUJUAN PENDIDIKAN DI INDONESIA}

Undang-UNDANG tentang sistem pendidikan Nasional tahun 2003 pada BAB I pasal 1 menguraikan bahwa pendidikan adalah usaha sadar dan terencana untuk mewujudkan suasana belajar dan proses pembelajaran agar peserta didik secara aktif mengembangkan potensi dirinya untuk memiliki kekuatan spiritual keagamaan, pengendalian diri, kepribadian, kecerdasan, akhlak mulia, serta keterampilan yang diperlukan dirinya, masyarakat, bangsa dan Negara. ${ }^{10}$ Selanjutnya pada pasal 3 di uraikan bahwa tujuan pendidikan nasional adalah untuk berkembangnya potensi peserta didik agar menjadi manusia yang beriman dan bertakwa kepada Tuhan Yang Maha Esa, berakhlak mulia, sehat, berilmu, cakap, kreatif, mandiri, dan menjadi warga Negara yang demokratis serta bertanggung jawab. ${ }^{11}$

${ }^{9}$ Hasbullah, Dasar-dasar Ilmu Pendidikan, Cet. X, (Jakarta : PT RajaGrafindo Persada, 2012), h. 138

${ }^{10}$ Anwar Arifin, Memahami Paradigma Baru Pendidikan Nasional Dalam Undang-Undang Sisdiknas,

Cet. II, (Jakarta : Ditjen Kelembagaan Agama Islam Depag, 2003). h. 34.

${ }^{11}$ Ibid. h. 37 


\begin{tabular}{ll}
\hline AL-QALAM & AL-QALAM \\
Jurnal Kajian Islam \& Pendidikan \\
Volume 8, No. 2, 2016 \\
ISSN (print) : 1858-4152 \\
ISSN (online) : xxxx-xxxx \\
Homepage : http://journal.iaimsinjai.ac.id/index.php/al-qalam \\
\hline
\end{tabular}

\section{STRUKTUR DAN JENIS PENDIDIKAN DI INDONESIA}

Pendidikan di Indonesia adalah seluruh pendidikan yang diselenggarakan di Indonesia, baik itu secara terstruktur maupun tidak terstruktur. Secara terstruktur, pendidikan di Indonesia menjadi tanggung jawab Kementerian Pendidikan Nasional Republik Indonesia (Kemdiknas), dahulu bernama Departemen Pendidikan dan Kebudayaan Republik Indonesia (Depdikbud). Di Indonesia, semua penduduk wajib mengikuti program wajib belajar pendidikan dasar selama sembilan tahun, enam tahun di sekolah dasar/madrasah ibtidaiyah dan tiga tahun di sekolah menengah pertama/madrasah tsanawiyah. Saat ini, pendidikan di Indonesia diatur melalui Undang-Undang Nomor 20 Tahun 2003 tentang Sistem Pendidikan Nasional.

Pendidikan di Indonesia terbagi ke dalam tiga jalur utama, yaitu formal, nonformal, dan informal. Pendidikan juga dibagi ke dalam empat jenjang, yaitu anak usia dini, dasar, menengah, dan tinggi. Pendidikan formal merupakan pendidikan yang diselenggarakan di sekolah-sekolah pada umumnya. Jalur pendidikan ini mempunyai jenjang pendidikan yang jelas, mulai dari pendidikan dasar, pendidikan menengah, sampai pendidikan tinggi. Pendidikan nonformal paling banyak terdapat pada usia dini, serta pendidikan dasar, adalah TPA, atau Taman Pendidikan Al Quran,yang banyak terdapat di setiap mesjid dan Sekolah Minggu, yang terdapat di semua gereja. Selain itu, ada juga berbagai kursus, diantaranya kursus musik, bimbingan belajar dan sebagainya. Pendidikan informal adalah jalur pendidikan keluarga dan lingkungan berbentuk kegiatan belajar secara mandiri yang dilakukan secara sadar dan bertanggung jawab.

Dari kelahiran sampai usia 3 tahun, kanak-kanak Indonesia pada umumnya tidak memiliki akses terhadap pendidikan formal. Dari usia 3 sampai 4 atau 5 tahun, mereka memasuki taman kanak-kanak. Pendidikan ini tidak wajib bagi warga negara Indonesia, tujuan pokoknya adalah untuk mempersiapkan anak didik memasuki sekolah dasar. Dari 49.000 taman kanak-kanak yang ada di Indonesia, 99,35\% diselenggarakan oleh pihak swasta. Periode taman kanak-kanak biasanya dibagi ke dalam "Kelas A" (atau Nol Kecil) dan "Kelas B", masing-masing untuk periode satu tahun.

Kanak-kanak berusia 6-11 tahun memasuki sekolah dasar (SD) atau madrasah ibtidaiyah (MI). Tingkatan pendidikan ini adalah wajib bagi seluruh warga negara Indonesia berdasarkan konstitusi nasional. Tidak seperti taman kanak-kanak yang sebagian besar di antaranya diselenggarakan pihak swasta, justru sebagian besar sekolah dasar diselenggarakan oleh sekolah-sekolah umum yang disediakan oleh negara (disebut "sekolah dasar negeri" atau "madrasah ibtidaiyah negeri"), terhitung 93\% dari seluruh sekolah dasar/madrasah ibtidaiyah yang ada di Indonesia. Sama halnya dengan sistem pendidikan di Amerika Serikat dan Australia, para siswa harus belajar selama enam tahun untuk menyelesaikan tahapan ini. Beberapa sekolah memberikan program pembelajaran yang dipercepat, di mana para siswa yang berkinerja bagus dapat menuntaskan sekolah dasar selama lima tahun saja.

Sekolah menengah pertama (SMP) dan madrasah tsanawiyah (MTs) adalah bagian dari pendidikan dasar di Indonesia. Setelah tamat dari SD/MI, para siswa dapat memilih untuk memasuki SMP atau MTs selama tiga tahun pada kisaran usia 12-14. Setelah tiga tahun dan tamat, para siswa dapat meneruskan pendidikan mereka ke 
sekolah menengah atas (SMA), sekolah menengah kejuruan (SMK), atau madrasah aliyah (MA).

Di Indonesia, pada tingkatan ini terdapat tiga jenis sekolah, yaitu sekolah menengah atas (SMA), sekolah menengah kejuruan (SMK), dan madrasah aliyah (MA). Siswa SMA dipersiapkan untuk melanjutkan pendidikannya di perguruan tinggi, sedangkan siswa SMK dipersiapkan untuk dapat langsung memasuki dunia kerja tanpa melanjutkan ke tahapan pendidikan selanjutnya. Madrasah aliyah pada dasarnya sama dengan sekolah menengah atas, tetapi porsi kurikulum keagamaannya (dalam hal ini Islam) lebih besar dibandingkan dengan sekolah menengah atas.

Setelah tamat dari sekolah menengah atas atau madrasah aliyah, para siswa dapat memasuki perguruan tinggi. Pendidikan tinggi di Indonesia dibagi ke dalam dua kategori: yakni negeri dan swasta. Kedua-duanya dipandu oleh Kementerian Pendidikan Nasional. Terdapat beberapa jenis lembaga pendidikan tinggi; misalnya universitas, sekolah tinggi, institut, akademi, dan politeknik.

\section{KURIKULUM PENDIDIKAN DI INDONESIA}

Pada era ini kurikulum yang dikembangkan diberi nama Kurikulum Berbasis Kompetensi (KBK). KBK adalah seperangkat rencana dan pengaturan tentang kompetensi dan hasil belajar yang harus dicapai siswa, penilaian, kegiatan belajar mengajar, dan pemberdayaan sumber daya pendidikan dalam pengembangan kurikulum sekolah (Depdiknas, 2002). Kurikulum ini menitik beratkan pada pengembangan kemampuan melakukan (kompetensi) tugas-tugas dengan standar performasi tertentu, sehingga hasilnya dapat dirasakan oleh peserta didik, berupa penguasaan terhadap serangkat kompetensi tertentu. KBK diarahkan untuk mengembangkan pengetahuan, pemahaman, kemampuan, nilai, sikap dan minat peserta didik, agar dapat melakukan sesuatu dalam bentuk kemahiran, ketepatan dan keberhasilan dengan penuh tanggungjawab.

Adapun karakteristik KBK menurut Depdiknas (2002) adalah sebagai berikut:

a. Menekankan pada ketercapaian kompetensi siswa baik secara individual maupu klasikal.

b. Berorientasi pada hasil belajar (learning outcomes) dan keberagaman.

c. Penyampaian dalam pembelajaran menggunakan pendekatan dan metode yang bervariasi.

d. Sumber belajar bukan hanya guru, tetapi juga sumber belajar lainnya yang memenuhi unsur edukatif.

e. Penilaian menekankan pada proses dan hasil belajar dalam upaya penguasaan atau pencapaian suatu kompetensi.

Kurikulum ini dikatakan sebagai perbaikan dari KBK yang diberi nama Kurikulum Tingkat Satuan Pendidikan (KTSP). KTSP ini merupakan bentuk implementasi dari UU No. 20 tahun 2003 tentang sistem pendidikan nasional yang dijabarkan ke dalam sejumlah peraturan antara lain Peraturan Pemerintah Nomor 19 tahun 2005 tentang standar nasional pendidikan. Peraturan Pemerintah ini memberikan arahan tentang perlunya disusun dan dilaksanakan delapan standar nasional pendidikan, yaitu: (1)standar isi, (2)standar proses, (3)standar kompetensi lulusan, (4)standar pendidik dan tenaga kependidikan, (5)standar sarana dan 


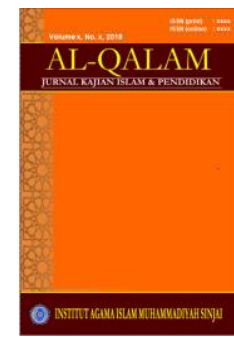

AL-QALAM

Jurnal Kajian Islam \& Pendidilkan

Volume 8, No. 2, 2016

ISSN (print) : 1858-4152

ISSN (online) : xxxx-xxxx

Homepage : http://journal.iaimsinjai.ac.id/index.php/al-qalam

prasarana, (6)standar pengelolaan, standar pembiayaan, dan (7)standar penilaian pendidikan.

\section{KESIMPULAN}

Pendidikan di Denmak dijiwai oleh prinsip prinsip dasar yang berlaku dalam kehidupan sosial budaya masyarakat Denmak seperti kebebasan berpendapat, self-control, persamaan serta saling mempercayai dan menghargai satu sama lain.

Berdasarkan pada beberapa pembahasan di atas, pendidikan di Denmark mengandung banyak sisi positif yang berguna bagi perkembangan mahasiswa baik dari sisi akademis mauapun non-akademis. Sisi positif ini dirasa masih jauh lebih banyak daripada sisi negatifnya.

Sampai saat ini belum banyak mahasiswa Indonesia yang melanjutkan pendidikan mereka ke Denmark. Mahasiswa Indonesia biasanya datang ke Denmark secara sporadis (sendiri-sendri tanpa dukungan dari badan kerja sama yang bisanya mengkoordinasi hal seperti ini, misalnya DAAD di Jerman dan STUNED di Belanda). Walaupun demikian, selama beberapa tahun terakhir beberapa mahasiswa Indonesia datang ke Denmark sebagai bagian dari program Erasmus Mundus (menghabiskan satu-dua semester di Denmark).

Adanya kerja sama antara pemerintah Indonesia dan Denmak akan memungkinkan lebih banyak mahasiswa Indonesia belajar di Denmark. Dengan adanya kerja sama formal, calon mahasiswa bisa mendapat informasi dan melakukan persiapan yang lebih baik untuk menunjang kesuksesan studinya di Denmark.

\section{DAFTAR PUSTAKA}

Anwar Arifin, 2003. Memahami Paradigma Baru Pendidikan Nasional Dalam UndangUndang Sisdiknas, Cet. II, Jakarta : Ditjen Kelembagaan Agama Islam Depag.

Agustian Syah Nur, 2012. Perbandingan Sistem Pendidikan 15 Negara, Cet Ii, Bandung:Lubuk Agung Bandung.

Hasbullah, 2012. Dasar-dasar Ilmu Pendidikan, Cet. X, Jakarta : PT RajaGrafindo Persada

M. Sukardjo dan Ukim Komaruddin, 2009. Landasan Pendidikan; Konsep dan Aplikasinya, Jakarta: PT. Rajagrafindo Persada.

http://id.wikipedia.org

www.uis.unesco.org

http://lifestyle.kompasiana.com/catatan/2011/04/22/belajar-dari-denmark/

http://en.wikipedia.org/wiki/Denmark

http://en.wikipedia.org/wiki/Danish_Folkeskole_Education

http://www.denmark.dk/en 